\title{
Modeling of Photovoltaic Grid Connected Generation System Based on Three Level NPC Converter
}

\author{
Francisco Javier Arcos-Pardo, José Luis Monroy-Morales, \\ Máximo Hernández-Ángeles \\ Programa de Graduados e Investigación en Ingeniería Eléctrica \\ Instituto Tecnológico de Morelia \\ Morelia, Michoacán México \\ Email:fcojarcospardo@ieee.org, jlmonroy_m@itmorelia.edu.mx, \\ mhernand_it@yahoo.com.mx
}

\author{
David Campos-Gaona \\ Wind Energy and Control Centre \\ University of Strathclyde \\ 99 George St, Glasgow G1 1RD, UK \\ Email: davidcg@ieee.org
}

\begin{abstract}
Renewable energy sources have been increasing and developing continuously in the last years, due to advantages over conventional generation sources. Photovoltaic (PV) systems generate electricity from sunlight without creating any air or water pollution and in a clean, quiet and reliable way. The efficiency and performance of $\mathrm{PV}$ systems are still under development. As a consequence, the control structures of the PV system gridconnected are a fundamental part for its proper functioning. In this paper, a grid connected photovoltaic system based on a three-phase three-level neutral point clamped (NPC) inverter is presented. The proposed system describes in detail each stage along with the suited controllers, which operate in a proper and efficient way. In addition, the Perturbation and Observation (P\&O) algorithm to get the maximum power point tracking (MPPT) of the PV system under different irradiation conditions, is proposed. In order to maximize the PV system power, a threephase three-level NPC converter is used to achieve higher power levels, lower voltage stress on devices, lower switching frequency and reduce harmonic content. In addition, $d-q$ reference frames are used to decouple the active and reactive power controllers. Simulations to validate the proposed procedures of the complete system are presented.
\end{abstract}

\section{INTRODUCTION}

The harmful effects caused by conventional power sources on the planet and the increasing energy demand have lead to the use of the natural resources as an alternative for energy production. [1]. Recently, the use of renewable energy sources have increased in order to solve the issues of growing energy consumption, the finite nature of fossil fuels and the worsening of the global environment [2]. Solar photovoltaic systems are widely known for the ability to generate electric power from the sunlight, and offer generated electricity in a clean, quiet and reliable way. Therefore, PV generation systems have been enhanced and considered as one of the most developed in power generation. These systems can work either in stand alone or grid connected mode.

The grid connected photovoltaic system has been widely implemented in electrical networks, however it is prone to affect the power quality of electrical networks by producing voltage sags, flicker, and harmonics. Also, solar energy is intermittent in nature and the power output from the PV modules changes with temperature and radiation levels. Therefore, the PV system controllers approaches must be able to solve the grid integration problems and extract the maximum power from PV generators under any weather conditions.

The voltage source inverters are an important component for renewable energy sources. Multilevel inverters are used in high-power and medium-voltage applications due to their competitive advantages over their two levels counterparts. Some of their advantages are, e.g., reduced switching-voltage ratings, smaller switching stresses $d v / d t$, an improved output voltage at lower switching frequencies and reduce harmonic currents generated by the inverter using an appropriate selection of switching vectors [3]. These characteristics have led to the development of many applications including PV systems where the multilevel topology allows to generate a wide range of output voltage levels [4]. Since the photovoltaic voltage output is a DC voltage, a DC-DC converter is used in order to shape the inverter voltage input and take advantage of a higher energy production. In addition, a MPPT (Maximum Power Point Tracking) controller is required to detect the PV system maximum power point tracking.

In this paper, a complete three-phase three-level NPC inverter grid-connected photovoltaic system, as shown in Fig. 1, is presented. The active and reactive power is controlled in accurate and appropriate way by mean of a NPC threelevel inverter in order to take advantages over conventional topologies. The mathematical model for grid-connection are described in a detailed manner.

\section{Photovoltaic Panel CONDitioning}

Connecting several solar cells in series or parallel is carried out in order to get proper power levels [5]. The PV systems drawbacks is that the solar radiation falling upon solar panels is not constant. The variation depends on many factors, e.g., 


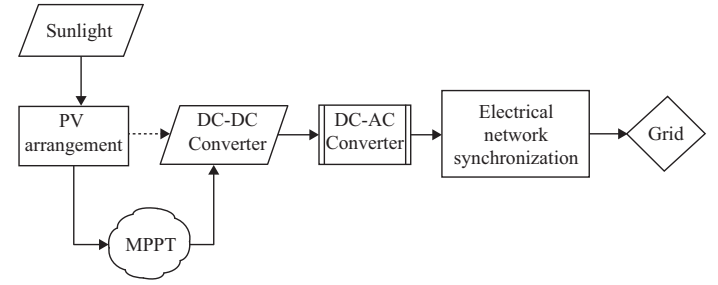

Fig. 1. PV system complete block diagram.

the area weather conditions where the PV is installed, which causes over-voltages or voltage and current drops. Therefore, a variable DC signal is closer to a real electrical signal generated by the sunlight, as shown in Fig.2. A variable

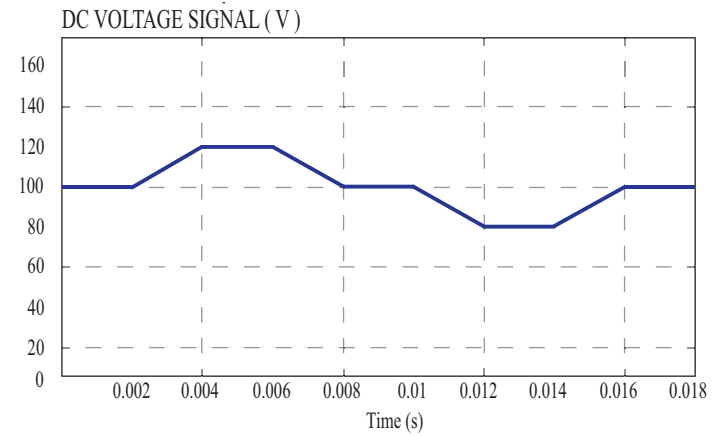

Fig. 2. DC signal conditioning.

DC signal enables having a quasi-realistic PV real behavior, plus the inclusion of sharp voltage level variations as sudden changes of elevations and falls in voltage can be represented as step response. In order to obtain the desired behaviors in the generated CD components, an arrangement of signals in time can be implemented as shown in Fig. 3. The generated and manageable signal must be transformed into a electrical signal through a simulation component.

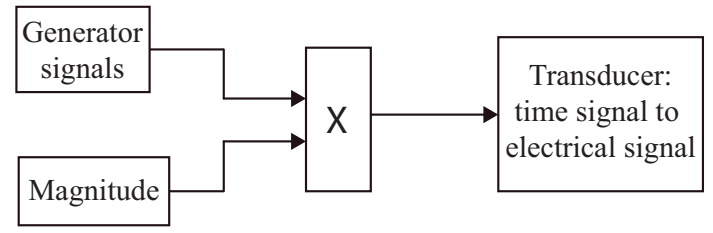

Fig. 3. Simulation diagram for the generated DC signal.

In Fig. 3, the magnitude block is a constant signal used to modify the amplitude of the generated signal. The generator signals block is programmed to obtain a desired waveform as shown in Fig. 2. A transducer is used to convert the generated signal into a electrical signal. The model presented in Fig. 3 is different from those previously studied where the PV panel is modeled based on solar cells maths equations [6]. However, the model presented in Fig. 3 allows analyze diverse and specific waveforms, including both those closer to real signals and the considered "hard testings". In this way, the complete system robustness is proved.

\section{DC-DC CONVERTER CONTROLlER}

In PV systems, a DC-DC converter is commonly used between the PV panel output and the inverter input. The DC-DC converter purpose is to adjust the voltage levels to feed the inverter. The Boost converter is useful for PV systems applications to obtain a better exploitation of the generated energy. The Boost converter is able to increase a $V_{s}$ output voltage from $V_{i n}$ input voltage.

Fig. 4 shows the Boost converter topology. A DC-DC con-

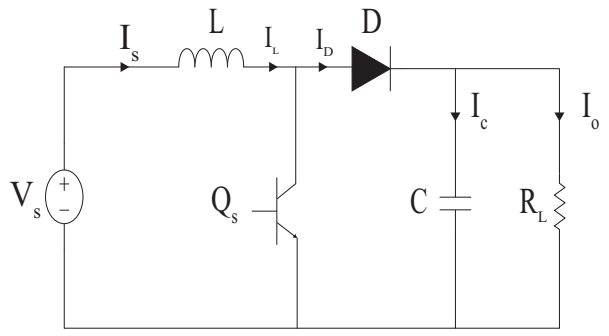

Fig. 4. Boost converter circuit.

verter adjusts the relationship $V_{i n} / V_{s}$ by mean of a control variable named duty cycle $(D)$,

$$
D=1-\frac{V_{i n}}{V_{s}}
$$

A MPPT algorithm is used to control the DC-DC converter duty cycle. The MPPT is the PV panel optimal operating point where the generated energy has the highest possible benefit [7]. The Boost converter control block diagram is shown in Fig. 5.

There are several methods to obtain the MPPT. Advanced

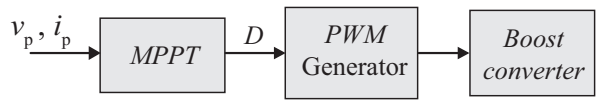

Fig. 5. Buck converter block diagram.

control algorithms are based on the $\mathrm{P} \& \mathrm{O}$ method since provides a fast and efficient control solution [8]. Therefore, the $\mathrm{P} \& \mathrm{O}$ algorithm is implemented in this paper, and is shown in Fig. 6.

The $\mathrm{P} \& \mathrm{O}$ algorithm compare the panel voltage and current with the immediately previous value of power to detect changes and adjust the duty cycle in an suitable way. Thus, a converter regulated signal output, by mean of a proper pulse wide modulation, is achieved.

\section{NPC THREE-LEVEL INVERTER}

A three-phase three-level NPC inverter is shown in Figure 7. Each phase share a common $D C$ bus, subdivided by two capacitors in three levels. The voltage across each capacitor is $V_{D C} / 2$; and the voltage stresses across each switching device and clamping diodes are limited to $V_{D C} / 2$. A three-level NPC is capable of providing five levels of line to line voltage and three levels of phase voltage. The NPC 


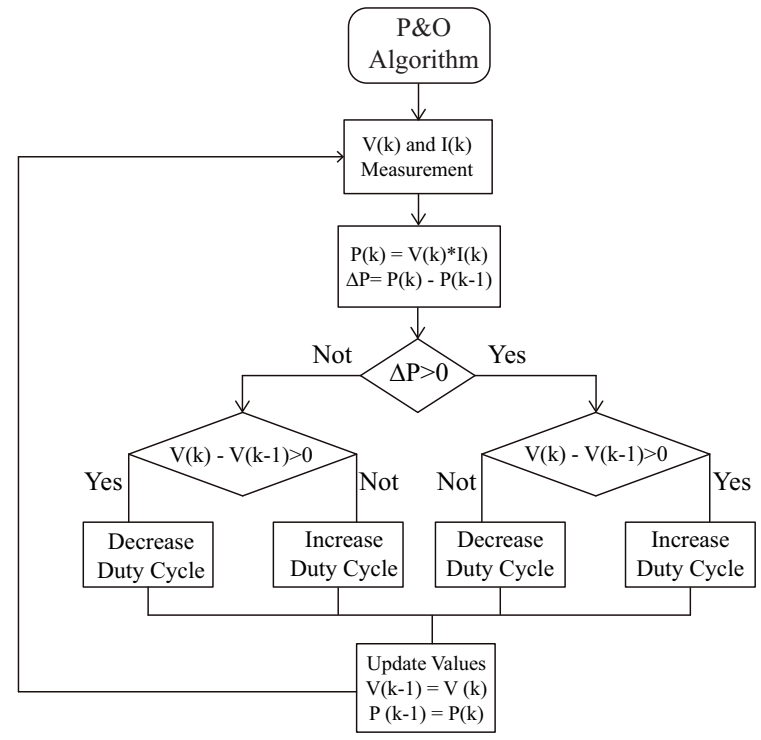

Fig. 6. $\mathrm{P} \& \mathrm{O}$ algorithm.

inverter reduces harmonics in both, current and voltage output.

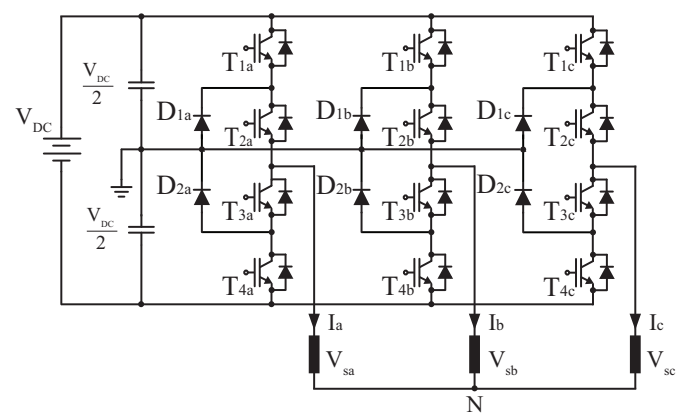

Fig. 7. Three-level NPC inverter topology.

Table I shows the switch states for phase $a$, and similar switching sequences can be derived for the remaining phases considering a displacement of $120^{\circ}$. Here, $T_{1 a}$ and $T_{3 a}$ are complementary between them and so on for $T_{2 a}$ and $T_{4 a}$. State condition 1/0 means switch ON/OFF conditions. In

TABLE I

SWITCHING STATES FOR A THREE-LEVEL NPC INVERTER

\begin{tabular}{|c|c|c|c|c|}
\hline \multicolumn{4}{|c|}{ States of switches } & Voltage \\
\hline$T_{1 a}$ & $T_{2 a}$ & $T_{3 a}$ & $T_{4 a}$ & $\begin{array}{l}\text { Level } \\
V_{a N}\end{array}$ \\
\hline 1 & 1 & 0 & 0 & $+V_{D C} / 2$ \\
\hline 0 & 1 & 1 & 0 & 0 \\
\hline 0 & 0 & 1 & 1 & $-V_{D C} / 2$ \\
\hline
\end{tabular}

Fig. 8 a detailed NPC inverter operation is shown. For phase $a$, three possibles switching states are required to have the three desired levels. Similar operation is for phases $B$ and $C$ taking in account the $120^{\circ}$ shifted.
The output voltage, $V_{s}^{k}$, can be calculated as,

$$
V_{s}^{k}=V_{D C}-\sum_{i=1}^{n^{k-1}} V_{T_{i}^{k}}
$$

where $n$ is the number of levels of the converter and $k$ stand for the phases $a, b$ and $c$. $V_{D C}$ is the converter DC input voltage and $V_{T_{i}^{k}}$ is the switching devices voltage drop,

$$
V_{T_{i}^{k}}=\left(1-T_{i}^{k}\right) V_{C i}
$$

$T i^{k}$ is corresponding to on or off switching device state, and $V_{C i}$ is the capacitors voltage connected in series.

Substituting equation (3) in equation (2), the output voltage from the switching signals is,

$$
V_{s}^{k}=\sum_{i=1}^{n^{k-1}} T_{i}^{k} V_{C i}
$$

The NPC optimal performance depends mainly of the
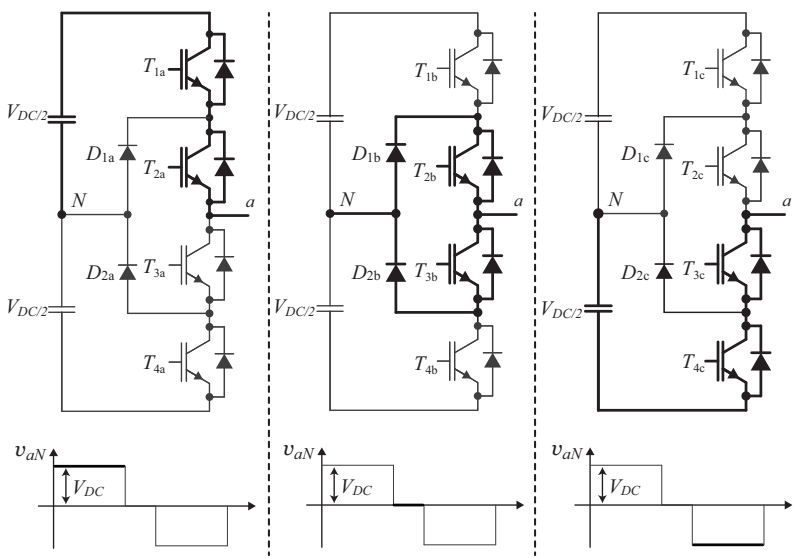

Fig. 8. Three-level NPC switching states, output voltages.

modulation technique. Sinusoidal Pulse Width Modulation (SPWM) technique is the most common method for inverter controlling due to presents some advantages to other modulation techniques as, output voltage harmonic content reduction, the power loss in the switching devices is low and can be easily implemented using a digital controller. Currently, the Phase Disposition $(P D)$, Phase Opposition Disposition $(P O D)$ and Alternative Phase Opposition Disposition (APOD) techniques have been developed. These carrier signal shifted techniques present some advantages depending on the shifted signal [9]. For the $A P O D$ and $P O D$ techniques, the arrangement for three-level inverters have an identical waveforms. Previous researches based on Fourier analysis show that PD technique present the lower harmonic content, therefore, the $P D$ technique is used in this paper. The $P D$ technique is shown in Fig. 9 


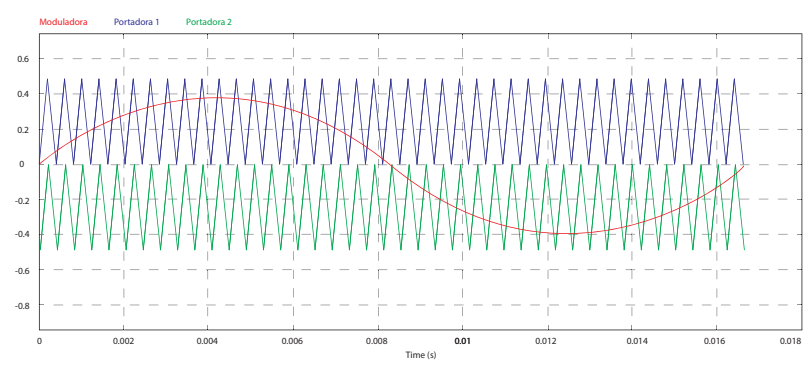

Fig. 9. Phase Disposition technique for three-level converter.

\section{GRID CONNECTED PV SYSTEM}

The inverter grid-connected diagram is shown in Fig. 10. The grid voltages and currents are become into DC signals by mean of $d-q$ transformation under balanced sinusoidal conditions and perfect synchronization [10]. The grid and inverter voltages are synchronized employing a phase-locked loop (PLL). Considering the inverter is connected to the grid,

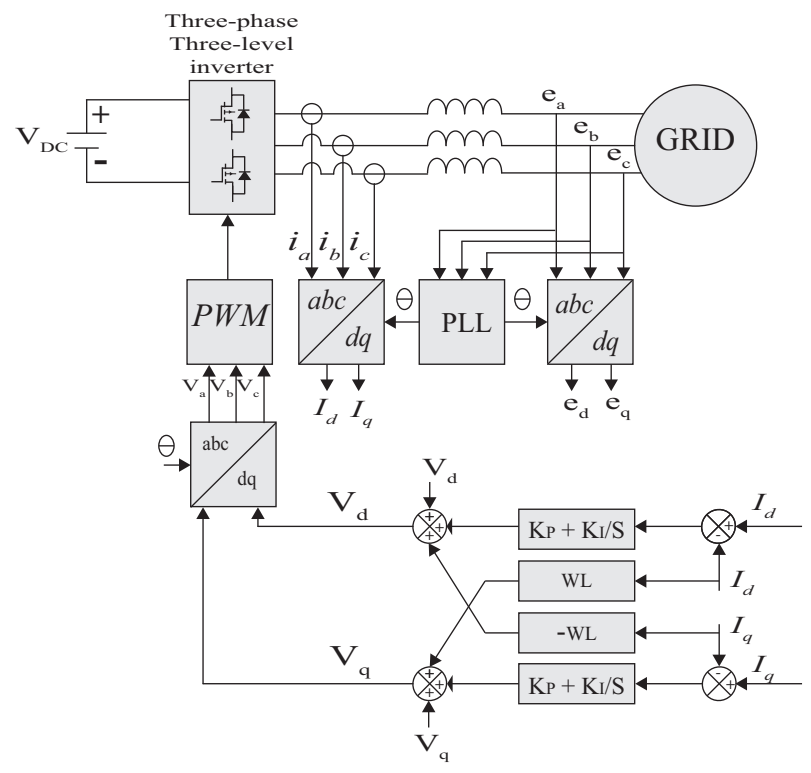

Fig. 10. Overall diagram of grid-connected converter control.

voltages and currents are defined as,

$$
v_{x}=R i_{x}+L \frac{d i_{x}}{d t}+v_{x_{i n v}}
$$

where $x=a, b$ and $c$.

$v_{x}$ and $i_{x}$ are $a c$ grid voltages and currents respectively and $v_{x_{i n v}}$ is the three-level inverter voltage. The three-level inverter is connected to the grid by mean of the resistance $R$ and the inductance $L$. The $a b c$ to $d-q$ transformation is applied to (5) and now the voltages and currents are expressed in two references frames, $d-q$, synchronously rotating at $A C$ frequency, $w_{c o p l}$, as shown in (6) and (7).

$$
v_{d}=R i_{d}+L \frac{d i_{d}}{d t}-w_{c o p l} L i_{q}+v_{d-i n v}
$$

$$
v_{q}=R i_{q}+L \frac{d i_{q}}{d t}+w_{c o p l} L i_{d}+v_{q-i n v}
$$

The $d$ and $q$ subscripts stand for the direct and quadrature axis, respectively.

Ecuations (6) and (7) have induced terms $w_{\text {copl }}$ Lid and $w_{\text {copl }} L i q$ that gives cross-coupling between the two axes. These cross-coupling terms can be taken as disturbances from control point view.

The power exchange in $d-q$ reference frame is given by,

$$
P=\frac{3}{2}\left(v_{d} i_{d}+v_{q} i_{q}\right)=v_{d c} i_{d c}
$$

where $v_{d c}$ and $i_{d c}$ are DC outputs voltages and currents. Equation (8) represents the power balance ratio between the $A C$ input and the $C D$ output. On the $D C$ side,

$$
i_{d c}=C \frac{d v_{C D}}{d t}+i_{L}
$$

In equation (8), the grid voltage vector can be defined to be along the $d$-axis direction, $v_{q}=0$. Therefore, the instantaneous real and reactive power can be calculated as,

$$
\begin{gathered}
p=\frac{3}{2} v_{d} i_{d} \\
q=-\frac{3}{2} v_{d} i_{q}
\end{gathered}
$$

As can be seen in equations (10) and (11), the active and reactive power are controlled by the $i_{d}$ and $i_{q}$ currents respectively. The PV system inverter control is carry out considering two PI control loops in cascade, a dc voltage controller providing reference signals to the control system and the current controller that generates the switching signals according to the reference and measured signals [11].

\section{A. Current Controller}

The current controller block diagram is shown in Fig. 11

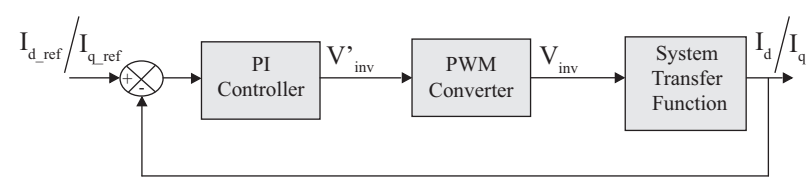

Fig. 11. Current controller block diagram.

Inside the PI controller block, there are two PI regulators, for the $d$ and $q$ axis current, respectively. After comparison, these PI controllers transform the error between the $d$ and $q$ current components into voltage magnitudes.

Equations (6) and (7) have a similar form, so that, only the $d$-axis equations are used for further analysis. Consequently the $q$-axis controller will also have the same parameters.

From Fig. 11, the equation for the $P I$ regulator is,

$$
\left\{i_{d r e f}(s)-i_{d}(s)\right\}\left(K_{p}+\frac{K_{i}}{s}\right)=v_{d-i n v}^{\prime}(s) .
$$


where $K_{p}$ and $K_{i}$ are the proportional and integral constants for current control.

The PWM converter block can be considered as an ideal power transformer with a time delay equal to half the switching cycle and produced by the inverter switches. Thus the PWM block is given as,

$$
Y(s)=\frac{1}{1+T_{a} s}
$$

where $T_{a}=T_{\text {switch }} / 2$.

The controller system have the reference signal and the feed forward signals in order to eliminate the cross coupling terms. Thus, the inverter voltage using these inputs are defined as,

$$
v_{d-i n v}^{\prime}=-\left(i_{d \_r e f}-i_{d}\right)\left(K_{p}+\frac{K_{i}}{s}\right)+w_{c o p l} L i_{q}+v_{d}
$$

Using the previous equations and Laplace transformation, the system transfer function is,

$$
G(s)=\left(\frac{1}{R+L s}\right)
$$

The modulus optimum method are used for tuning the current controller, this method is widely used because of simplicity and fast response.

\section{B. Voltage Controller}

The voltage controller general block diagram is shown in Fig. 12. The voltage controller is composed by PI voltage controller, current controller and the system transfer function where the capacitor is the principal element.

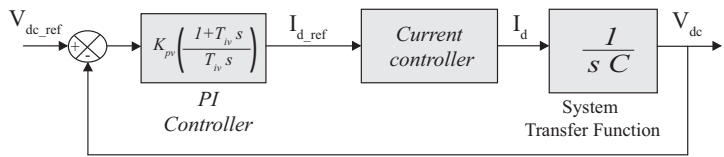

Fig. 12. General block diagram of $v_{d c}$ controller.

For the $P I$ controller in the Laplace domain, is:

$$
\left\{V_{d c \_r e f}(s)-V_{d c}(s)\right\}\left(K_{p v}+\frac{K_{i v}}{s}\right)=i_{d \_r e f}(s) \text {. }
$$

The subscript " $v$ " denotes the voltage regulator.

The simplification of the second order transfer function of the current controller, by equivalent first order transfer function can be approximated as

$$
W(s)=\frac{1}{T_{e q} s+1}
$$

where $T_{e q}=2 T_{a}$.

Assuming $V_{q}=0$ in equation (8), the relationship between $i_{d}$ and $I_{d c}$ is,

$$
I_{d c}=\left(\frac{3}{2}\right)\left(\frac{V_{d}}{V_{d c}}\right) i_{d}
$$

Equation (18) defines the current gain value. Therefore, the voltage controller controls the capacitor current so as to maintain the power balance.

The overall control block diagram of the $d c$ voltage controller is as shown in Fig. 13. For tuning the voltage controller, the

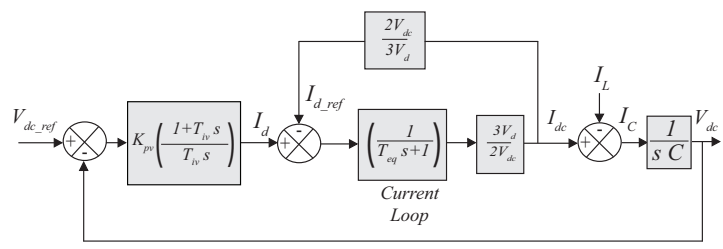

Fig. 13. Closed loop control diagram of $d c$ voltage controller.

symmetrical optimum method are used.

\section{Simulation RESUlts}

In order to verify the system performance, simulations based on Fig. 1 were carried out. A varying-time $D C$ signal which can closest describe the PV behaviour is shown in Fig. 14. As shown in this figure, the $D C$ voltage value is $300 \mathrm{v}$ with $\pm 10 V_{D C}$ variations.

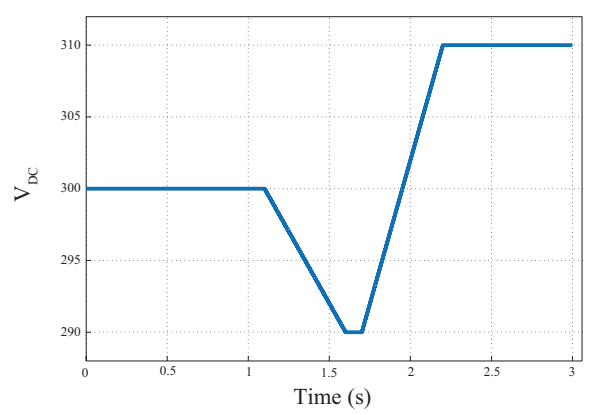

Fig. 14. Generated input voltage supplied to grid-connected system.

As can seen from Fig. 1, the PV panel is fed for a signal as that shown in Fig. 14. As mention before, solar energy is intermittent in nature and the power output from the PV modules changes with the radiation levels. Consequently, the simulation of $D C-D C$ converter output voltage when a MPPT algorithm is not considered was carried out and is shown en Fig. 15. Due to the above, a $D C-D C$ boost converter is required to regulate the $\mathrm{DC}$ voltage applied to the inverter.

The photovoltaic voltage variations leads to no proper behaviour in the dc-dc converter when no control in duty cycle is performed. Therefore, the $D C-D C$ converter duty cycle must be controlled by a MPPT algorithm, otherwise, the $D C-D C$ converter output will have voltage and current variations originated by solar irradiation. The regulated $D C$ output voltage using the $P \& O$ MPPT algorithm is shown in Fig. 16. The boost converter raises from $300 V_{C D}$ to $500 V_{C D}$.

The active and reactive power control was carried out. Figures 17 and 18 shows changes in the active and reactive power 


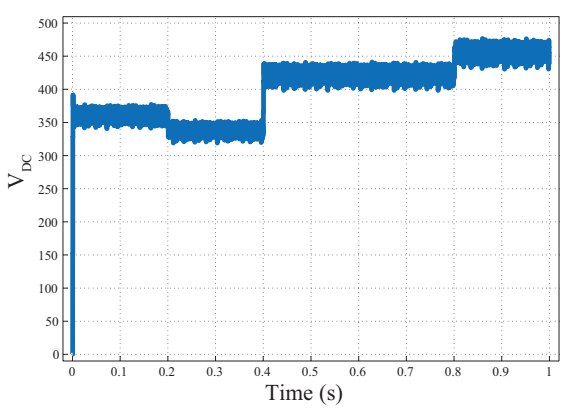

Fig. 15. Boost converter output voltage without MPPT control.

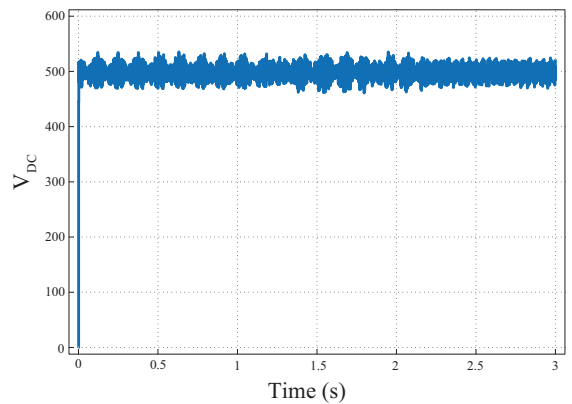

Fig. 16. Boost converter output voltage controlled by MPPT.

references, respectively. In Fig. 17, the measured and reference active power are shown when the reference value changes in three different values, $\mathrm{P}=800 \mathrm{w}, \mathrm{P}=1,200 \mathrm{w}$ and $\mathrm{P}=1,000 \mathrm{w}$. In the same way, different changes in the reference reactive power are simulated as shown in Fig. 18. In this figure, the measured reactive power tracks the reference reactive power value in $\mathrm{Q}=100, \mathrm{Q}=-100$ and $\mathrm{Q}=0$, which is the desired value for system. As seen in Figs. 17 and 18, the used controller allows the reference active and reactive power proper tracking. Important to mention that the maximum active power injected to the grid depends on the panel photovoltaic capabilities.

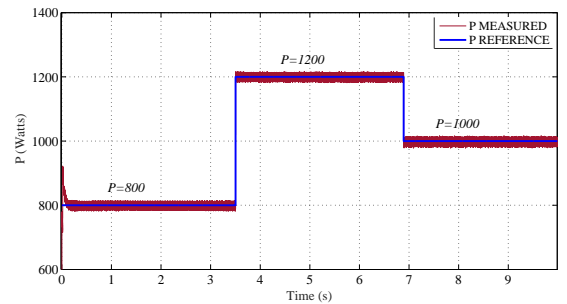

Fig. 17. Boost converter output voltage controlled by MPPT.

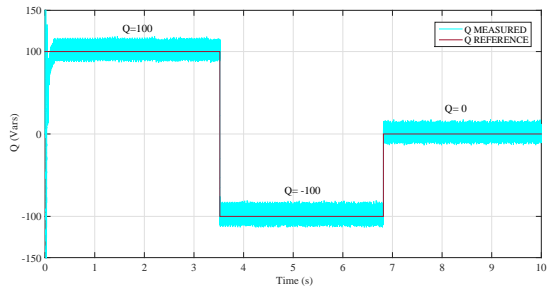

Fig. 18. Boost converter output voltage controlled by MPPT

\section{CONCLUSIONS}

A grid connected PV system is a viable solution provide energy from renewable sources. These systems generate electricity from sunlight without pollution. This paper describes all the elements of a grid connected PV system. The $D C$ $D C$ converter along with MPPT algorithm leads to have regulated voltage and therefore an NPC inverter appropriate performance.

In addition, the used NPC topology, allows handle higher power. For active and reactive power control, the $d-q$ reference frames are applied to provide a decoupled control. Moreover, power electronics has proved the possibility to implement a PV systems because of high switching device development. Simulations results have proved the good performance of the proposed system along with the controllers rules.

\section{REFERENCES}

[1] H. Reham, AEI Aroudi, ACid-Pastor, G. Gar'lca, C. Olalla and L. Salamero, Impedance Matching in Photovoltaic Systems Using Cascaded Boost Converters and Sliding-Mode Control, IEEE Transactions on power electronics, Vol. 30, No. 6, June 2015.

[2] M. Dali, D. Belhadj and X. Roboam, Hybrid solar-wind system with battery storage operating in grid-connected and standalone mode: Control and energy management-experimental investigation, Energy, vol. 35 2010, pp. 2587-2595.

[3] José Luis Monroy-Morales, David Campos-Gaona, Máximo HernándezÁngeles, Rafael Peña-Alzola and José Leonardo Guardado-Zavala, An Active Power Filter Based on a Three-Level Inverter and 3D-SVPWM for Selective Harmonic and Reactive Compensation, Control and Communication in Distributed Generation Systems, Energies 2017, 10(3), 297; doi:10.3390/en10030297.

[4] Goetz, S.; Zhongxi, L.; Liang, X.; Zhang, C.; Lukic, M.; Peterchev, A.V., Control of modular multilevel converter with parallel connectivity-Application to battery system. IEEE Trans. Power Electron. 2016, doi:10.1109/TPEL.2016.2645884.

[5] Roger A. Messenger and Jerry. Ventre, Phtovoltaic Systems Engineering, 2nd ed. Florida, USA: CRC PRESS, 2005.

[6] Gow, J. A. and Manning, Development of photovoltaic array model for use in power electronics studies, IEE Proceedings on electric power applications, 1999.

[7] R. Sridhar and N. Thamizh Selvan and S. Jeevananthan and P. Sujith Chowdary, Performance improvement of a photo voltaic array using $M P P T(P \& O)$ technique, INTERNATIONAL CONFERENCE ON COMMUNICATION CONTROL AND COMPUTING TECHNOLOGIES, 2010.

[8] William Christopher and R. Ramesh, Comparative Study of $P \& O$ and InC MPPT Algorithms, American Journal of Engineering Research (AJER), 2013.

[9] Ilhami Colak and Ersan Kabalci and Ramazan Bayindir, Review of multilevel voltage source inverter topologies and control schemes, Elsevier, 2010.

[10] F. N. Gakis, S. A. Papathanassiou, "Simple control schemes for grid-connected three-phase voltage-source inverters of DG units", Proc.XVII International Conference on Electrical Machines, ICEM'2006, 2-5Sept.2006 Chania, Greece.

[11] C. Bajracharya, M. Molinas, J. A. Suul, T. M. Undeland , "Understanding of tuning techniques of converter controllers for VSC-HVDC", NORPIE/2008, Nordic Workshop on Power and Industrial Electronics, June 9-11, 2008 